\title{
A dumbbell spinal mass derived from ectopic thyroid
}

\author{
Shiyuan Han ${ }^{1 \#}$, Fei Xie ${ }^{1 \#}$, Yongning $\mathrm{Li}^{1}$, Yan You ${ }^{2}$, Zhimin $\mathrm{Li}^{1}$, Xin Wang ${ }^{1}$, Jun Gao ${ }^{1}$ \\ ${ }^{1}$ Department of Neurosurgery, ${ }^{2}$ Department of Pathology, Peking Union Medical College Hospital, Chinese Academy of Medical Sciences and \\ Peking Union Medical College, Beijing 100730, China \\ \#These authors contributed equally to this work. \\ Correspondence to: Dr. Jun Gao; Dr. Yongning Li. Department of Neurosurgery, Peking Union Medical College Hospital, Chinese Academy of \\ Medical Sciences and Peking Union Medical College, Shuaifuyuan 1, Dong Cheng District, Beijing 100730, China. \\ Email: edisonted1226@sina.com; liynpc@163.com.
}

\begin{abstract}
Ectopic thyroid is a defect of embryologic development characterized by dislocation of the gland with or without an orthotopic thyroid gland, among other developmental issues. We report about an ectopic thyroid condition featured as an epidural dumbbell-shaped mass at the T6-7 level, also, with another gland located pre-tracheally. However, thyroid ectopy usually occurs along the trajectory of the embryologic migration of the thyroid, which is far from where the spine and spinal cord originate. To our knowledge, this is the first case reporting an ectopic thyroid tissue masquerading as a spinal neurogenic tumor but that the tumor was later confirmed to be an ectopic follicular variant of papillary thyroid carcinoma (FVPTC). Spinal epidural ectopy is a serious matter and we discuss some plausible explanations that may further our understanding of origination of ectopic thyroid.
\end{abstract}

Keywords: Spinal dumbbell tumor; thyroid dysgenesis; ectopic thyroid; papillary thyroid carcinoma

Submitted Sep 13, 2019. Accepted for publication Jan 04, 2020.

doi: 10.21037 /gs.2020.01.15

View this article at: http://dx.doi.org/10.21037/gs.2020.01.15

\section{Introduction}

On a neurosurgical note, a dumbbell lesion that causes widening of neural foramen and neurological compromise with cord or nerve compression is usually a benign peripheral nerve sheath tumor, such as a schwannoma, or more rarely, an angiolipoma. Ectopic thyroid tissue is an infrequently encountered anomaly caused by abnormal development and disturbed migration of the gland from base of the tongue to the pre-tracheal area in utero (1). Ectopy can often be detected in the tongue, neck, and mediastinal region. The genetic and molecular basis underlying spinal epidural ectopic thyroid carcinoma remains difficult to comprehend, and further discussion of both anatomic and embryological factors is necessary. Only limited reports of ectopic conditions have described malignant transformations of the ectopic tissue. Most of these reports have covered papillary carcinomas. Here, we report a 69-year-old woman with a thoracic epidural mass alongside her spinal cord, which was later confirmed an ectopic follicular variant of papillary thyroid carcinoma (FVPTC).

\section{Case presentation}

A 69-year-old woman suffered from persistent left back pain (below the left scapula) for 2 months. An MRI showed a dumbbell mass with contrast enhancement at the T6-7 level and a CT scan showed bone destruction around the lesion (Figures 1,2). In the local hospital, she underwent a fineneedle aspiration of the lesion and the histopathological report simply showed that collected specimen from spinal lesion was similar to thyroid gland. Thus, she went for our institution for a further diagnosis and treatment. Her neurologic examination demonstrated negative results. She had undergone partial thyroidectomy 15 years prior and histopathology showed thyroid cysts within the right lobe. During follow-up, an ultrasonic examination revealed multiple thyroid nodules graded as TI-RADS 3, and her thyroid function was normal. After hospitalization, she 


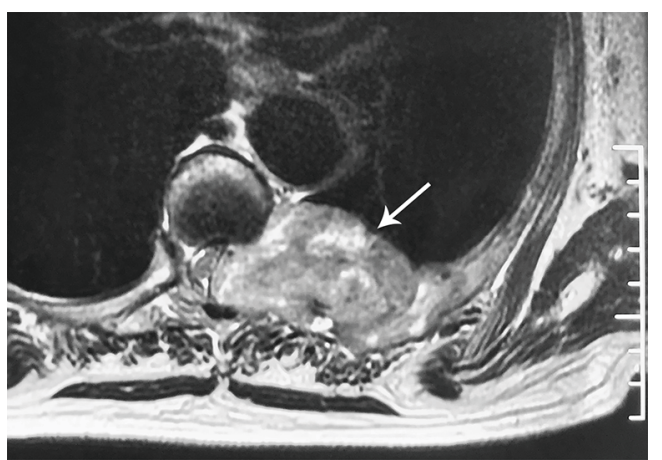

Figure 1 T2-weighted axial MRI image demonstrating a left epidural mass (white arrow) protruding from the left neural foramen with severe spinal cord compression.

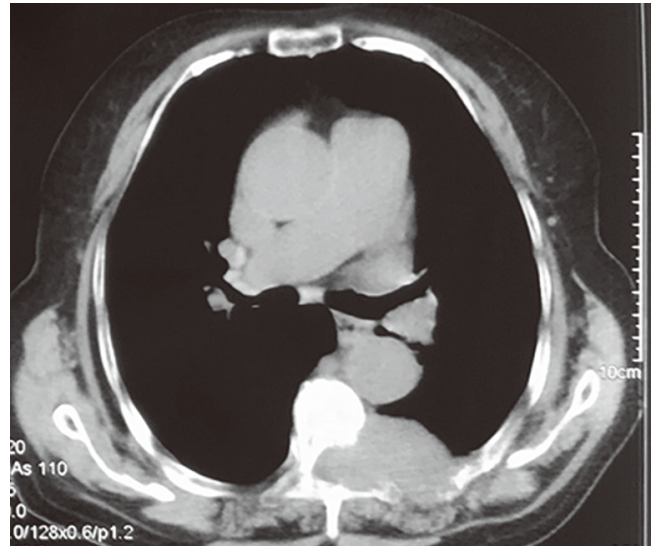

Figure 2 Thoracic CT scan showing enlarged neural foramen and bone destruction.
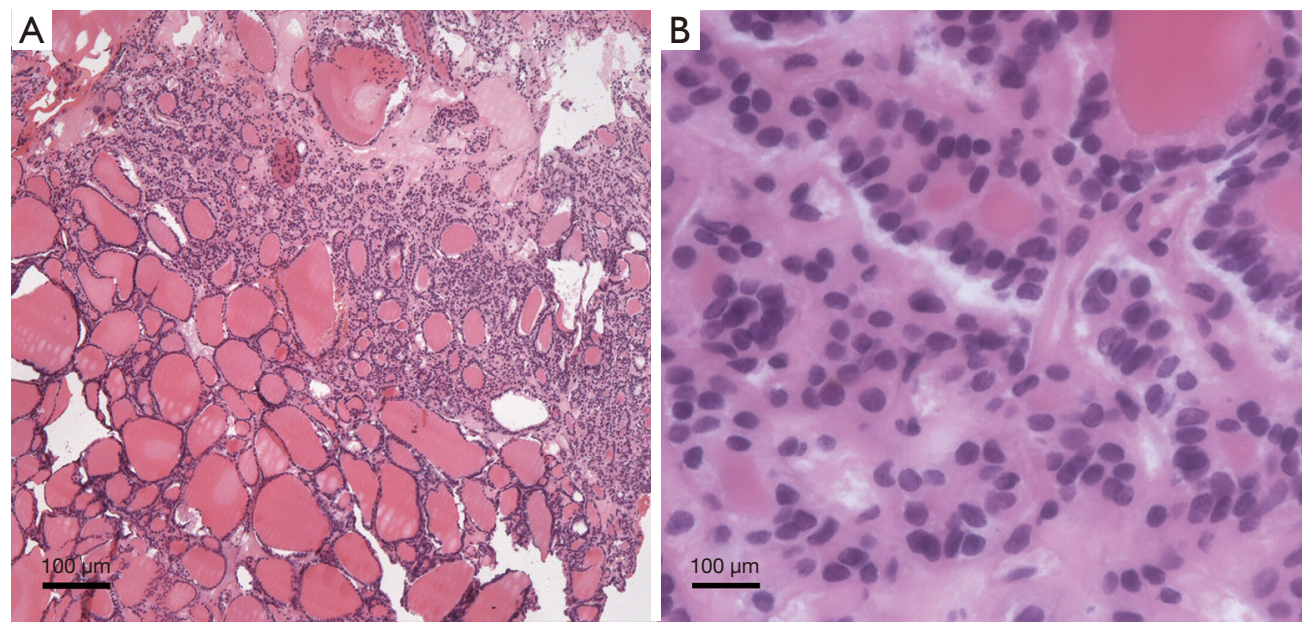

Figure 3 Histopathological results of the tissue. (A) Photomicrograph showing normal thyroid follicles (original magnification, $\times 40$ ). (B) Photomicrograph showing a nuclear ground-glass appearance, crowding, and grooving (H\&E stain, original magnification $\times 400)$.

underwent a decompression and exploration operation, and a soft, extremely vascularized epidural lesion was found. The mass widened the left T6-7 neural foramen and eroded the neighboring osseous tissue. Histopathological results with hematoxylin-eosin (H\&E) staining showed groundglass nuclei with crowding and a grooved appearance (Figure 3). Normal thyroid follicles were found around the neoplastic tissue. In this case, however, papillae were absent, and a follicular architectural pattern was present. Immunohistochemical analysis showed positive TTF-1, Thy, and Ki-67\% (index 5\%). The patient was diagnosed with an ectopic FVPTC. All of her symptoms were alleviated after surgery.

She developed a worsened soreness in the same site 12 months after the surgical intervention, and her very recent MRI showed further evolvement of the lesion (Figure 4). However, she refused to accept any further treatment.

\section{Discussion}

Thyroid ectopia is a developmental disorder that refers to improper location of the gland. Incidence of thyroid ectopia ranges from 0.3 to 1 case per 100,000 population with a female preponderance. The risk of malignant transformation 

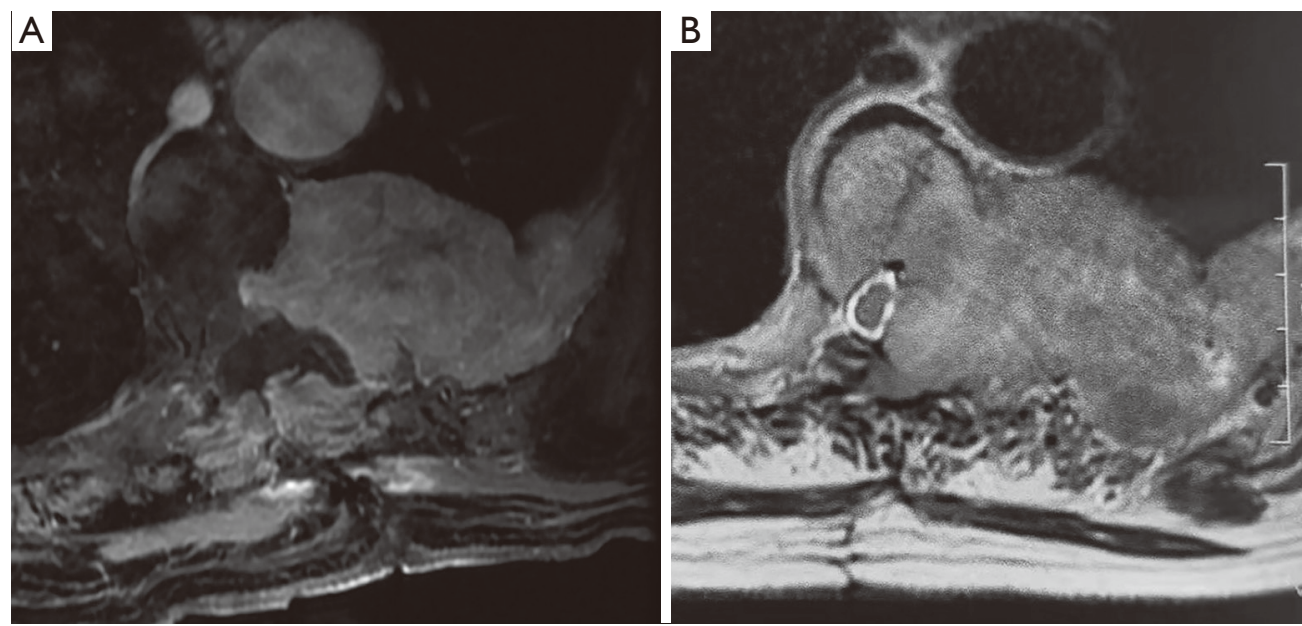

Figure 4 Post-operative images of the patient. (A) Immediate post-operative MRI showing partial removal of the mass. (B) T2-weighted axial MRI a year after the surgery showing re-growth of the mass.

accounts for only $1 \%$ of all reported ectopic thyroids (2). Papillary carcinoma is the paramount histologic type in ectopic tissue, and it is the most commonly encountered thyroid cancer in the normal orthotopic gland. The human thyroid gland originates from thickening of endodermal epithelium, which is termed midline thyroid anlage (MTA), at anterior foregut. Endoderm cells form the anlage and are progenitors of thyroid follicles that later fulfill the central function of the thyroid gland's hormone production. Then cells inside in tandem with adjacent mesenchyme form a diverticulum with a narrow neck that connects the migrating precursor thyroid tissue to the pharyngeal floor (3). The connective duct gradually disappears and the gland expands laterally and descends continuously. Ectopic thyroids develop along the path of migration journey from foramen cecum to the mediastinum and approximately $90 \%$ of ectopic thyroid tissue is found in the base of the tongue. However, as the procedure and final completion is under control of interactions between the thyroid itself and neighboring embryonic tissues, a few cases have shown ectopic thyroid glands in the heart, hepatic region, adrenal gland, or ovary (4-7). Some reports covered transformation from parathyroid bodies, whose precursors migrate from the neural crest to thyroid follicles during embryonic life (3).

The terms mass effect and hypothyroidism cover a majority of clinical presentations that lack specificity, and an ectopia faces every problem a thyroid could generate. The relatively benign results of ultrasonic testing (TI-
RADS 3) and normal structures of thyroid follicle in the specimen eliminated the possibility of malignant metastasis from the orthotopic thyroid. Thus, our case remains the first concerning ectopic thyroid tissue that developed malignancy and was mistaken for spinal cord neoplasia. The ectopic FVPTC presented as an epidural mass protruding from thoracic neural foramen and finally evolved to a large intra-thoracic mass, which has never been reported before.

Here, we indicate some putative trace of ectopic thyroid originating alongside the spinal cord. (I) Initiative of thyroid genesis is mainly regulated by expression of Titf1/ Nkx2-1, Foxe1, Pax8, and Hhex, and dysregulation of these transcription factors also plays an unequivocal role in thyroid cancer (8). The launch of MTA may be activated by some of the transcription factors, especially Pax8, which is also expressed in correlation with spine and spinal cord formation. (II) In some rare cases, C cell precursors or a portion of them fail to migrate from the neural crest. Instead, they form spinal nerves and other related structures and develop with them (9). Finally, these stubborn cells fail to develop parathyroid bodies but rather form thyroid follicular cells, which has been covered in some reports (3). (III) Spinal ectopia of the gland may be disseminated by errors in the inductive signals required in thyroid migration, and a part of thyroid primordium fails to descend to the settled passage or location.

Thyroid ectopia may happen occultly or with actual or imminent thyroid dysfunction including, in most cases, 
hypothyroidism and compensatory hyperplasia due to a great occurrence of absent orthotopic thyroid. Diagnosis can be based on physical examination, ultrasonography, or other auxiliary tests. Positron emission tomography/ computed tomography (PET/CT) and emission computed tomography (ECT) can help clinicians spot and identify ectopic glands and evaluate systemic status. CT scan and MRI enable the delineation of soft tissues with contrast. Optimal treatment modalities for an ectopic thyroid depend on tumor site and size, patient age and sex, comorbidity, hormone status, and other correlating factors. An asymptomatic ectopia or euthyroid condition warrants no treatments (10). Usually, levothyroxine replacement suffices for cases of hypothyroidism alone. However, when a patient complains about the mass effect in their body parts combined with severe thyroid dysfunction or the ectopic gland show signs of malignant transformation, radical interventions are necessary. As with normal thyroid tumors, a surgical approach and radioiodine therapy are often the best way to remove the lesion and are considered the standard of care $(11,12)$. It is necessary to examine the orthotopic thyroid via cervical ultrasonography before total surgical resection to prevent permanent hypothyroidism.

We here report a case of ectopic thyroid mimicking a spinal dumbbell tumor, which has never been described before. A benign peripheral nerve sheath tumor or a metastasis from thyroid should be considered in patients in whom there is no reason to suspect spinal ectopia. Mechanisms underpinning ectopic thyroid remain to be fully determined and those underlying ectopia growing both within and outside the spinal canal are likely to be multifactorial.

\section{Acknowledgments}

We thank LetPub (www.letpub.com) for its linguistic assistance during the preparation of this manuscript.

Funding: None.

\section{Footnote}

Conflicts of Interest: All authors have completed the ICMJE uniform disclosure form (available at http://dx.doi. org/10.21037/gs.2020.01.15). The authors declare no potential conflicts of interest.
Ethical Statement: The authors are accountable for all aspects of the work in ensuring that questions related to the accuracy or integrity of any part of the work are appropriately investigated and resolved. Written informed consent was obtained from the patient for publication of this Case report and any accompanying images. A copy of the written consent is available for review by the Editor-inChief of this journal.

Open Access Statement: This is an Open Access article distributed in accordance with the Creative Commons Attribution-NonCommercial-NoDerivs 4.0 International License (CC BY-NC-ND 4.0), which permits the noncommercial replication and distribution of the article with the strict proviso that no changes or edits are made and the original work is properly cited (including links to both the formal publication through the relevant DOI and the license). See: https://creativecommons.org/licenses/by-nc-nd/4.0/.

\section{References}

1. Nilsson M, Fagman H. Development of the thyroid gland. Development 2017;144:2123-40.

2. Jensen PH, Pilt AP, Wittendorff HE. [Ectopic thyroid tissue with a primary carcinoma]. Ugeskr Laeger 2017;179:

3. De Felice M, Di Lauro R. Thyroid development and its disorders: genetics and molecular mechanisms. Endocr Rev 2004;25:722-46.

4. Landeta F, Hoffmeier A, Fuchs M, et al. Ectopic thyroid mass in the heart. Lancet 2012;379:1762.

5. Romero-Rojas A, Bella-Cueto MR, Meza-Cabrera IA, et al. Ectopic thyroid tissue in the adrenal gland: a report of two cases with pathogenetic implications. Thyroid 2013;23:1644-50.

6. Schmidt J, Derr V, Heinrich MC, et al. BRAF in papillary thyroid carcinoma of ovary (struma ovarii). Am J Surg Pathol 2007;31:1337-43.

7. Ghanem N, Bley T, Altehoefer C, et al. Ectopic thyroid gland in the porta hepatis and lingua. Thyroid 2003;13:503-7.

8. Dupain C, Ali HM, Mouhoub TA, et al. Induction of TTF-1 or PAX-8 expression on proliferation and tumorigenicity in thyroid carcinomas. Int J Oncol 2016;49:1248-58.

9. Bronner ME, Simoes-Costa M. The Neural Crest Migrating into the Twenty-First Century. Curr Top Dev 
Biol 2016;116:115-34.

10. Oomen KP, Modi VK, Maddalozzo J. Thyroglossal duct cyst and ectopic thyroid: surgical management. Otolaryngol Clin North Am 2015;48:15-27.

11. Mogi C, Shinomiya H, Fujii N, et al. Transoral

Cite this article as: Han S, Xie F, Li Y, You Y, Li Z, Wang X, Gao J. A dumbbell spinal mass derived from ectopic thyroid. Gland Surg 2020;9(2):447-451. doi: 10.21037/gs.2020.01.15 videolaryngoscopic surgery for papillary carcinoma arising in lingual thyroid. Auris Nasus Larynx 2018;45:1127-9.

12. Gandhi A, Wong KK, Gross MD, et al. Lingual Thyroid Ectopia: Diagnostic SPECT/CT Imaging and Radioactive Iodine Treatment. Thyroid 2016;26:573-9. 